\title{
Puerto Rico: pueblo en vilo, 1898-2004*
}

Ivette Pérez Vega

Facultad de Humanidades

Universidad de Puerto Rico

\section{Resumen}

En este artículo se plantea la interrogante sobre el futuro de Puerto Rico como estado libre asociado de Estados Unidos y el debate en el país sobre este tema desde 1917.

Palabras claves: Puerto Rico, dependencia de Estados Unidos, república asociada, colonialismo

\begin{abstract}
In this article, the author puts the question about the future of Puerto Rico under the questions of free associated state of USA, as well as the debate in Puerto Rico on this topic from 1917.
\end{abstract}

Keywords: Puerto Rico, dependence on USA, associated republic, colonialism

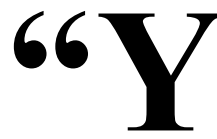

en los momentos más graves nuestras decisiones vacilan en un ir y venir sin reposo buscando su acomodo. Nuestras rebeldías son momentáneas; nuestra docilidad permanente."1

El interés de escribir sobre el estatus de Puerto Rico surgió al encontrar un documento sobre una entrevista de Roberto H. Todd, líder del Partido Republicano Puertorriqueño, favorecedor de la estadidad para Puerto Rico, al prominente congresista (N. Y.) Senador Elihu Root, en

* Ponencia presentada en el VII Congreso Internacional de Estudios latinoamericanos, IDELA (Universidad Nacional), Universidad La Serena (Chile), San José, Costa Rica, 9-12 de noviembre de 2004.
Washington en 1912. Todd ofreció información valiosa a Estados Unidos (E.U.) sobre Puerto Rico, situación que facilitó la invasión que había culminado en la toma de la isla como botín de guerra por esa nación en $1898 .^{2}$ Me reveló el documento que la posición tomada por E. U. desde entonces hasta el presente sobre Puerto Rico (P. R.) no ha cambiado fundamentalmente. Las palabras de Root son tan contundentes al decirnos que el Congreso nunca le daría la estadidad a Puerto Rico y que la isla debería ser, algún día, "una república con un protectorado americano".

Las palabras del gobernador de la isla, George W. Davis, al Presidente Mckinley 
en 1899 son muy reveladoras al respecto: "Puerto Rico, diferente a otras repúblicas, nunca ha sido, no es, y probablemente nunca será independiente. Es ahora una posesión de E.U. y así continuará hasta que el Congreso decida otro estatus que pueda concederle, lo que estará en control del Congreso."

La isla no es un territorio tan importante para Estados Unidos, ni nuestro estatus es un "issue" de tanta prioridad para el Congreso. Pero, debido a la situación política en que ha estado nuestro país en este año, E. U. se vio obligado a abandonar en su totalidad su principal lugar de entrenamiento militar (Isla de Vieques) por la oposición del pueblo de Vieques y de P. R., y decidió también clausurar su más importante y última base militar (Roosevelt Roads) en el país. Tal parece que quiere deshacerse de $P$. R. porque ha perdido su utilidad inmediata para ellos: la militar. Con la desaparición de sus principales intereses en la isla, Puerto Rico no es de interés para esa nación.

E. U. a través de un siglo nunca ha tenido la intención de hacer a P. R. un estado de la Unión o darle la soberanía plena o la independencia. Por tanto, cuando lo crea oportuno, le otorgará el estatus de una "república con un protectorado" norteamericano, es decir, una "república asociada" a E. U., según expresó Root hace 92 años; E. U. nunca había estado dispuesto ni quería desprenderse de Puerto Rico, pero ahora, pienso que el estatus de una república asociada se nos conferirá más pronto de lo que el pueblo cree.

En 1912, P. R. dependía prácticamente en su totalidad de las decisiones de la metrópoli o de sus representantes en la isla; gobierno que en la realidad no ha cambiado grandemente, con la excepción de obtener la ciudadanía norteamericana en 1917, concedida para su conveniencia, para justificar la utilización de los puertorriqueños como soldados en la Primera Guerra Mundial. De esta forma, los puertorriqueños, complacidos con su nueva ciudadanía, participarían en la defensa de E. U. y así se sentirían parte de esa gran nación. Ese fue el paso utópico que acercó e "integró" a los puertorriqueños a E. U. El pueblo de Puerto Rico creyó que era parte del coloso del Norte, no sabía que sólo le pertenecía.

Por otra parte, Root consideraba, igual que otros congresistas, a los puertorriqueños incapaces de gobernarse a sí mismos bajo la nueva política norteamericana, ${ }^{4}$ ya que la Constitución no aplicaba a los territorios porque estaban sujetos a la soberanía plena del Congreso sin otra limitación legal que la dispuesta en el tratado de cesión. ${ }^{5}$ Una de las principales razones para tal oposición era por prejuicios raciales, lo que daba lugar a la negativa de una posible estadidad para P. R., oposición que todavía prevalece en el Congreso. ${ }^{6}$

Afirma el artículo IX del Tratado de Paz de 1898, en el que España cede P. R. a E. U.: "los derechos civiles y el estatus político de los habitantes de los territorios estarán determinados por el Congreso".7 Como países soberanos, el poder que tuvo España para ceder su colonia, lo tiene E. U. de cederlo a otro país sin consultar al pueblo, porque tiene poderes plenarios sobre la isla. Este, interpretado con lo que dispone la Constitución de E. U. (art. IV, 3) sobre 
los territorios, y la del Tribunal Supremo Federal en 1907: El Congreso tiene el poder de disponer y establecer todas las reglas necesarias para sus territorios como cualquier propiedad perteneciente a los E. U.; "tiene toda la autoridad legislativa sobre el pueblo de los territorios y de sus departamentos", ${ }^{8}$ revelando así el poder soberano del Congreso sobre Puerto Rico, con el poder de cualquier decisión sobre sus derechos civiles, como también sobre su ciudadanía, estatus político y economía.

Desde 1901-22, la Corte Suprema de E. U. (Casos Insulares) reconoció que "el Congreso tenía una autoridad más amplia sobre P. R. que sobre cualquier otro estado al no estar incorporado." queños estaban muy preocupados de que estando la isla a merced de esa nación, el Congreso tuviera el poder de determinar su destino. Confirmándolo así el Juez Fuller de la Corte Suprema: "El Congreso tiene el poder de mantener a P. R. como un territorio no incorporado en un estado de ambigüedad por un período indefinido." $Y$ en ese estado de ambigüedad quedó P. R. "E1 Tribunal Supremo ha resuelto repetidas veces que E.U. como nación soberana tiene poder inherente para adquirir y gobernar territorios y disponer de ellos. Los territorios son de entera creación del Congreso y los tribunales del territorio ejercen su poder mediante la autoridad que les confiere el Congreso." ${ }^{\prime 10}$

Esta ambigüedad de los puertorriqueños y de sus líderes políticos en al no saber cuál estatus desean para P. R. está aún presente en el país. La ambigüedad como la indecisión son típicas del colonizado. ${ }^{11}$ Ese sentir del puertorriqueño de querer una independencia con la ciudadanía norteamericana perdura en la psiquis del pueblo. Quizás por eso es que la gran mayoría de los independentistas hoy día desean conservar la ciudadanía norteamericana. La ambigüedad también se reflejaba entre los líderes políticos favorecedores de la estadidad al declarar que si E. U. no otorgaba la estadidad sí querían la independencia. De manera similar lo han manifestado en el presente líderes del movimiento que favorecen la estadidad. Ya que casi la mitad de la población ha demostrado su preferencia por la estadidad, el Congreso se está viendo comprometido a decidir el estatus del país.

Desde antes de 1912, se ha estado oyendo la eterna queja entre los puertorriqueños de que la ciudadanía norteamericana fue de "segunda clase". El puertorriqueño no tiene los mismos derechos políticos y económicos que el norteamericano en Estados Unidos: no puede votar por el presidente de E. U., no tiene voto en el Congreso y sólo tiene un representante, el Comisionado Residente. Aunque muchos la consideren de "segunda", la mayoría del pueblo desea continuar portando el pasaporte norteamericano, aun si E. U. le diera la independencia a P. R.

El Congreso al aprobar la Ley Jones, en 1917, afirmó y lo confirmó la Corte Suprema Federal que la ciudadanía no significó "la incorporación de P. R. a la Unión en calidad de territorio"; "la incorporación no se presume sin una expresa declaración; ha sido siempre un paso importante para lograr la estadidad." 12 Nos damos cuenta de que la política norteamericana desde 1900 no varió. Desde entonces, E. U. no 
ha estado dispuesto a permitir ni la separación de P. R. de éste, ni su ingreso como estado a la Unión. Ha sido una "política ad hoc a los problemas, de orientación pragmática, carente de orientación o plan, de la que arranca en buena parte la ambivalencia y confusión puertorriqueña en cuanto a su destino de pueblo". ${ }^{13}$

La polémica situación de Puerto Rico sobre el estatus colonial ha trascendido al plano internacional en la ONU. Aunque E.U. declaró en 1953 ante la ONU que P.R. no era colonia (luego de establecido el Estado Libre Asociado), y aceptado por dicha organización, todos los años los partidos políticos de la isla protestan sobre su estado colonial en ese foro mundial ante el Comité de Descolonización. Este ha reinstalado el caso de P. R. de forma tácita en la lista de las colonias. "La creación del ELA no significó la intención del Congreso de modificar el estatus territorial de la misma." 14

Mientras la opresión "tácita" norteamericana continúe indiferente por el pueblo y los problemas social y económico en la isla se resuelvan, la relación política existente con Estados Unidos permanecerá en un segundo plano para los puertorriqueños. Para muchos políticos no hay prisa en resolverla porque todavía creen que: "Puerto Rico ocupa una relación con los E. U. sin paralelo en nuestr8a historia."15 Tal parece que P. R. ha podido mantener esa relación tan especial y mantener ese statu quo, logrando así congelar el estatus, hasta el presente, de Estado Libre Asociado. Ese ha sido el mayor triunfo del ELA.

Cuánto le importe al pueblo puertorriqueño ser un país independiente sin ataduras con los norteamericanos o ser parte total de esa nación como un estado no está todavía de forma urgente en la agenda norteamericana. El precio de ambos estatus es alto en lo económico, sociocultural y en lo político tanto para P.R. como para E.U. Por otra parte, para un pueblo democrático como es P.R., será difícil continuar con el estatus del ELA, sin representación en el Congreso y sin poderes para resolver sus problemas económicos y sociales. Pero, con la ambigüedad del pueblo puertorriqueño y la actitud del Congreso, la solución del estatus podría ser pospuesta indefinidamente. Mientras Estados Unidos no presente a P. $R$. un cuadro claro de su real intención con la isla, el estatus no se resolverá.

El ELA tiene la "necesidad de eliminar de nuestra asociación con E. U. todo vestigio -sea real o aparente- de colonialismo. Es interesante recordar que desde el establecimiento del ELA en 1952, las decisiones del Supremo Federal han demostrado que la Corte veía dicho estatus como uno de gobierno propio - un self government."16 Sin embargo, últimamente, hemos observado como hecho notorio que el Congreso ha reconocido casi expresamente el carácter colonial de la condición política de P. R. al plantearse la exclusión o eventual eliminación de la condición actual del territorio (Estado Libre Asociado o "Commonwealth") como alternativa descolonizadora. Así lo demostró cuando el Congreso consideró la definición del ELA en el Proyecto Young como un estatus colonial, al presentarse como fórmula descolonizadora para el plebiscito en P. R. en 1998. ¿Demuestra el hecho su intención de imponerle a Puerto Rico una independencia asociada a los E. U.? 
Puerto Rico continúa siendo un territorio no incorporado a esa nación, sometido a los poderes plenos de ésta por más de cien años, y la Constitución Federal no se extiende a P. R. por ser un territorio. Según lo determinaron las Cortes Federales, sólo la Carta de Derechos establece que: "Estamos ante la realidad en que la voluntad del Congreso prevalece por encima de nuestra Constitución y cualquiera otra interpretación en contrario de este Foro judicial."17 Si el estatus del Estado Libre Asociado es territorial, ${ }^{18}$ es colonial, como lo ha reconocido el Congreso en 1998. Y según plantearon los congresistas en el Proyecto Young, el ELA no contiene un pacto bilateral o convenio inalterable dentro de la unión permanente con E. U. ${ }^{19} \mathrm{Si}$ el ELA es considerado por el Congreso un estado transitorio, entonces la unión de P. R. con E. U. no es permanente, y su durabilidad sólo podría ser determinada por el Congreso. "La fórmula del ELA como una "solución final" se torna más insípida, obsoleta e improductiva." 20

Expresó el Tribunal Supremo Federal: "Los territorios son gobernados por leyes estatutarias del Congreso, unilateralmente enmendadas y revocadas sólo por el Congreso". "El Congreso, el cual tiene el poder bajo la Cláusula Territorial de la Constitución para hacer todas las Reglas o Reglamentos necesarios con respecto al territorio perteneciente a E. U., puede tratar a P. R. de manera distinta a los estados siempre que exista una base racional para su acción." ${ }^{21}$ El Congreso tiene el poder absoluto de concederle la independencia o una "república asociada" a P. R. sin ninguna consulta al pueblo puertorriqueño. ¿Tiene Estados Unidos otra razón válida para querer desprenderse en parte de P. R. y darle una "república" asociada? Seguramente. ${ }^{22}$ Puerto Rico le cuesta al Tesoro Federal más de $\$ 14$ billones por año, lo que puede ser una razón de gran peso para el gobierno norteamericano de considerar dicho estatus. ${ }^{23} \mathrm{El}$ presupuesto de P.R. es de \$21 billones.

¿Es la posición estratégica de Puerto Rico en el Caribe todavía tan importante y necesaria para Estados Unidos luego de la Guerra Fría? No lo creo. La importancia militar pasada que tuvo Puerto Rico para Estados Unidos ya no existe. Quizás, sólo le interesaría por los soldados que puede reclutar para la guerra o como puerto de transbordo entre Latinoamérica y Europa. Pero eso sólo lo decidirá Estados Unidos según sus intereses.

No puede el pueblo puertorriqueño olvidar que E. U. controla el país en todos sus aspectos: "el problema primario (como en los demás órdenes de la vida puertorriqueña) es que el gobierno federal ejerce en P. R. sus vastos poderes, sin los puertorriqueños por medio de sus votos, en la aprobación de las leyes pertinentes y en la elección o nombramiento de los funcionarios encargados de ponerlas en vigor. Estados Unidos ejerce sus poderes conforme con sus necesidades y objetivos y sin tomar en cuenta la enorme densidad poblacional y la débil economía de Puerto Rico." 24

¿Podrá Puerto Rico bajo el estatus de Estado Libre Asociado conseguir un acuerdo aceptable con Estados Unidos que no constituya una anexión colonial y así mantenerse como fórmula descolonizadora en un futuro plebiscito? Ante este panorama 
político, hoy día el estatus sí está en issue en la isla. Difícilmente pueda prevalecer en un futuro un ELA "casi soberano"; sí sería factible una "libre asociación" a E. U. o una independencia asociada como la han propuesto estadolibristas. ${ }^{25}$ Ante la problemática del Partido Popular de la definición del estatus de ELA como una "república asociada" a esa nación, los líderes que apoyan dicho estatus tendrán que expresar qué clase de ciudadanía (norteamericana o puertorriqueña o ambas) quieren para el pueblo y buscar una definición del estatus que esté cónsono no sólo con el derecho internacional y el norteamericano, sino con el pueblo de P. R.

Si P. R. se convierte en una "república asociada" a E. U. o en una independiente y soberana, entonces la ciudadanía norteamericana sería derogada o revocada del país y quedaría P. R. con su ciudadanía puertorriqueña que siempre ha tenido. Los puertorriqueños tienen ciudadanía dual, la de Puerto Rico y la de Estados Unidos. ${ }^{26}$

Ahora, después de más de un siglo, temerosa está todavía la mayoría del pueblo de que el Congreso podría despojarlos de su estatus y su ciudadanía norteamericana si se le confiere a P. R. el estatus de una "república asociada" o el de una independiente y soberana. ${ }^{27}$ ¿Habría la posibilidad de que P. R. como "república asociada" a E. U. tenga ciudadanía dual? ¿Permitiría E. U. una relación con P. R. como "república asociada" cuando la mayoría de sus habitantes tuviese ciudadanía estadounidense? Solamente el Congreso tiene la autoridad para responder esas preguntas. Conceder una categoría de república asociada representa grandes problemas para E. U. ya que una gran parte de la población de Puerto Rico, por el miedo a una independencia, se iría a vivir a ese país.

Puerto Rico, que aparentemente se dirige hacia su descolonización bajo la dirección del gobierno local (ELA) ${ }^{28}$ y grupos políticos, tendrá que decidir su fórmula descolonizadora, como también lo tendrá que hacer finalmente en el futuro el Congreso. Ante la compleja situación que confrontan tanto P. R. como E. U., se demuestra que hay una urgente necesidad de revisar las relaciones existentes entre la isla y la metrópoli, y una determinación del estatus por el Congreso. Este ofrecerá, a su conveniencia, una solución "para ponerle fin al sistema colonial en Puerto Rico, para darle una base moral, profundamente respetable a la relación entre Estados Unidos y Puerto Rico". ${ }^{29}$ Se trata del reconocimiento, finalmente, de la personalidad jurídica de Puerto Rico por esa nación.

\section{Notas y bibliografía}

1 Antonio S. Pedreira, Insularismo. San Juan, Biblioteca de Autores Puertorriqueños, 1950.

2 Colección Roberto H. Todd, Universidad del Sagrado Corazón, San Juan, P. R. Doc. 1-017:2, 1912.

3 Angel Rivero, Crónica de la Guerra Hispanoamericana en P.R., San Juan, Sucesiones de Rivadeneyra, S.A., 1922.

4 Informe anual del Gobernador de Puerto Rico al Presidente William M. McKinley, sometido el 13 de octubre de 1899: Report of Brig. Gen. George W. Davis, Civil Affairs of Puerto Rico, 1899. Washington D.C., Government Printing Office, 1900. 
5 Congress. Rec., H. R. Report of the Secretary of War, 1899. 56th Congress, 1st S., H.R. Doc. no.2, pp. 26-29.

6 José Trías Monge, Historia Constitucional de Puerto Rico, Río Piedras, Editorial Universidad de P. R., 1980.

7 Jaime B. Fuster, "The Origins of the Doctrine of Territorial Incorporation and its Implications Regarding the Power of the Commonwealth of Puerto Rico to Regulate Interstate Commerce", 42 Rev, Jur. U.P.R. 258, 1974).

8 Efrén Rivera Ramos, "The Legal Construction of American Colonialism: The Insular Cases (1901-1922)", 65 Rev. Jur. U.P.R. 225 (1996).

9 David M. Heldfeld, "Historical Prelude to the Constistution of the Commonwealth of Puerto Rico", 21 Rev. Jur. U.P.R. 3(1952).

10 National Bank v. County of Yankton, 101 U.S. 333 (1907).

11 Downes v. Bidwell, 182 U.S. 244 (1901)

12 Grafton v. U.S., 206 U.S. 333 (1907); U.S. v. Kagarna, 118 U.S. 375 (1886).

13 Rene Marqués, "El puertorriqueño dócil”. Ensayos. San Juan, Editorial Antillana, 1969.

14 Balzac v. People of Puerto Rico, 258 v. U.S. 298 (1922)

15 Efrén Rivera Ramos, "The Legal Construction of American Colonialism: The Insular Cases 1902-1922”, 65 Rev. Jur. U.P.R. 225 (1996).

16 Marta Figueroa Torres, "The Validity of a Statutory Limitation on the Territorial Power of Congress: Puerto Rico Revisited", 1991.
17 Fermín Arraiza Navas, "Auto determinación y P.R.” 31 Rev. Jur. Univ. Interamericana 2 (1997).

18 Rivera Rodríguez v. Partido Popular, 457 U.S. 1 (1952).

19 Rodríguez Meléndez v. Sup. Amigo, Inc., 126 D.P.R. 92 (1990).

20 Arnold Leibowitz, "The Applicability of Federal Law to the Commonwealth of P.R", Rev. Jur. U.P.R. 615 (1968).

21 U.S. v. Valentine, 288 F. Supp. 957 (D.P.R. 1968). 48 U.S.C. 867 o sec. 44 Federal Relations Act.

22 Gordon K. Lewis, "El problema del status quo", 22 Colegio de Abogados 523 (1961-62). Freedom of Power in the Caribbean. N.Y., M.R. Press, 1963.

23 Harris v. Rosario, 446 U.S. 651 (1980), p. 651-652. Califano v. Torres, 435 U.S. 1 (1978); Torres v. P.R., 442 U.S. 465 (1979).

24 C. Gautier Mayoral y M. Argüelles, Puerto Rico y la O.N.U, Río Piedras, Edil, 1978.

25 Kal Wagenheim, Perfil de Puerto Rico, Barcelona, Ed. Destino, 1973.

26 Congress. Rec., H.R. 105th. Cong. 1st S., Feb 27,1997. Don Young, U.S. Political Status Act, H.R. 856.

27 Miguel Hernández Agosto, Autonomía en Tratado de Unión con los Estados Unidos, inédito, San Juan, 1997.

28 Antonio Femós Cepero, "La ciudadanía nacional de los puertorriqueños", 30 Rev. Jur. Universidad Interamericana 3 (1996), La ciudadanía nacional de los puertorriqueños, San Juan, Ediciones Situm, 1996.

29 David M. Heldfeld, "How Much of the Federal Constitution is Likely to be Held Applicable to the Commonwealth 
of Puerto Rico?, 39 Rev. Jur. U.P.R. 2 (1970).

30 Arnold Leibowitz, "The Commonwealth of Puerto Rico Trying to Gain Dignity and Maintain Culture", 17 Rev. Jur. U.P.R. (1982-83).

31 Ramírez de Ferrer v. Mari Brás, CT96-14 (1996), p. 38-49. Civil KAC 960856 (906).

28 Raymond Carr, Puerto Rico: A Colonial Experiment, New York, Vintage Books, 1984.
29 Luis Muñoz Marín. Colección Roberto Sánchez Vilella, "El Status Político de Puerto Rico: Discursos pronunciados por Don Luis Muñoz Marín", 3 de junio y 4 de junio de 1959.

30 Miguel Hernández Agosto, Autonomía en Tratado de Unión con los Estados Unidos, inédito, San Juan, 1997. 